\title{
Editors' Introduction
}

What is 'natural'? While social scientists thought the 'nature-nurture' debate had long been superseded, as had the distinction between the natural and the artificial and all the other related dichotomies, the question of the natural persists and insists, perhaps more than ever, in an age where almost all features of human and animal life seem open to technical modification. We are therefore pleased to publish, as our lead article in this issue, a stimulating lecture on this theme by Evelyn Fox Keller, whose qualifications as a biologist, philosopher and historian of biology make her supremely qualified to comment on the shifting status, role and meaning of 'the natural'. While many of the questions and dilemmas around 'the natural' arise these days because of technological innovation and intervention at the beginning - and even at the creation-of life, we must also increasingly confront the question, 'What is natural?' at the end of life. Is there such a thing as a natural death any more, when such a large proportion of deaths occur in hospital or medical settings? In a provocative argument questioning the principle of the sanctity of life, and the distinction often made between letting die and active bringing to death, Emily Jackson argues that, for those without religious beliefs, the adherence of the law to the sanctity principle has no coherent basis, often generates unnecessary suffering, and should be interrogated if not discarded.

Of course, the issue of medical intervention which might actually cause death is highly contentious, and runs counter to what many feel are the basic principles of medical ethics. Carl Elliott returns us to an earlier debate about medical ethics, focusing on research ethics, and reminds us of the pioneering critique of Maurice Pappworth, on human guinea pigs in the 1960s, whose implications reverberate today (although now concerns about the subjects of medical research are often pacified by the routine bureaucratic procedures of ethics committees). In a different vein, Simon Cohn reports on what it is like to be one such human guinea pig, here in the entirely ethical setting of a brain mapping study seeking the neural correlates of pleasure. In this ethnographic account, Cohn reminds us of something so often forgotten in reports of imaging studies-that the laboratory is not a 'non-situation' for the subject of the research. In fact, subjects actively try to make sense of the procedures they are being subjected to, and their participation in the research involves a subtle orientation to the wishes and desires of the experimenters.

The issue of ethics arises in a third way in Stefan Ecks' analysis of corporate ethics and the claims of pharmaceutical companies to be 'good citizens', driven by higher aspirations than profits alone. Ecks focuses on the lawsuit brought by the drug company Novartis against the Indian government over the patent for the anti-cancer drug Glivec. The lawsuit caused an international outcry. Ecks shows how citizenship arguments were deployed by both sides of this case, and argues that while the Indian High Court dismissed Novartis' challenge, Novartis actually won a more important battle: to protect the Euro-American markets for Glivec.

Another key area of contemporary biomedical innovation concerns the growth of genetic tests to be used in clinical settings, either to confirm diagnoses or to decide on the drug to be prescribed. Adam Hedgecoe examines a phenomenon that has often led to criticism of clinicians-their frequent reluctance to make use of such tests. Hedgecoe argues that this reluctance should not be dismissed as either ignorance or short-sighted clinical resistance, 
but often arises from a well founded judgement by clinicians that the results of such a test have low clinical utility. The question of when to use such tests and what therapeutically useful information they provide, is coming to the fore as part of the age of personalized medicine, in which the number of such tests is increasing and their costs falling.

Our final two papers in this issue address a theme discussed in a previous issue of BioSocieties-forensic DNA databases. Jay Aronson considers the history of the DNA typing regime used in the United States, and the key role played by the FBI in shaping the nature and characteristics of the testing techniques used. And Bronwyn Parry, one of the authors of the recent Nuffield Council Report on The forensic use of bioinformation, writing in her personal capacity, responds to the discussions in our journal and elsewhere that followed the publication of that report, pointing in particular to the problems and challenges that arise when forensic DNA databases are located, as they are, within global circuits of crime control and global circuits for the exchange of biological samples.

Finally, our books forum is dedicated to Steven Epstein's recent book Inclusion: The politics of difference in medical research. In Inclusion, Epstein describes the institutionalization in the United States of a particular way of attending to difference in medical research: one in which the classification of bodies according to race and sex is paramount, particularly in the organization and interpretation of clinical trials. Epstein offers a subtle critique of the long-term consequences of these efforts, originally intended to increase the visibility of groups-minorities and women-traditionally under-represented in medical research. Two formidable scholars, Troy Duster and Vololona Rabeharisoa, offer their thoughts on Epstein's book, to which Steven Epstein himself then responds. 